\title{
Determination of the Correlation between the Air Temperature Measured in Situ and Remotely Sensed Data from MODIS and SEVIRI in Congo-Brazzaville
}

\author{
Maixent Olivier C. Kambi ${ }^{1,2,3 *}$, Zhenhui Wang1,2, Georges Gulemvuga ${ }^{3}$ \\ ${ }^{1}$ Collaborative Innovation Center on Forecast and Evaluation of Meteorological Disasters, CMA Key Laboratory for \\ Aerosol-Cloud-Precipitation, Nanjing University of Information Science \& Technology, Nanjing, China \\ ${ }^{2}$ School of Atmospheric Physics, Nanjing University of Information Science \& Technology, Nanjing, China \\ ${ }^{3}$ Water Resources Management, International Commission of Congo-Ubangi-Sangha Basin, D. R. of Congo \\ Email: *maixentkambi@gmail.com
}

How to cite this paper: Kambi, M.O.C., Wang, Z.H. and Gulemvuga, G. (2018) Determination of the Correlation between the Air Temperature Measured in Situ and Remotely Sensed Data from MODIS and SEVIRI in Congo-Brazzaville. Atmospheric and Climate Sciences, 8, 192-211.

https://doi.org/10.4236/acs.2018.82013

Received: November 22, 2017

Accepted: April 10, 2018

Published: April 16, 2018

Copyright $\odot 2018$ by authors and Scientific Research Publishing Inc. This work is licensed under the Creative Commons Attribution International License (CC BY 4.0).

http://creativecommons.org/licenses/by/4.0/

\begin{abstract}
This study compared data from the MODerate-resolution Imaging Spectroradiometer (MODIS) onboard NASA's Terra satellite and the Spinning Enhanced Visible and Infrared Imager (SEVIRI) on EUMETSAT's Meterosat Second Generation (MSG) satellite with in situ data obtained from ground observation stations in Congo-Brazzaville. Remote sensing instruments can be used to estimate air temperature, which has an important role in monitoring the effects of climate change. Congo-Brazzaville is located in equatorial forest, which is difficult to access, and has a limited number of ground meteorological stations measuring air temperature. This study used MODIS and MSG data for the period 2009-2014 to assess the performance of land surface temperature data from satellites against in situ data from ground-based stations in Congo-Brazzaville using a linear regression model. This work has allowed us to determine which satellite is best adapted for use in Central Africa.
\end{abstract}

\section{Keywords}

Air Temperature, Land Surface Temperature, MODIS, MSG, Tropical Climate, Central Africa

\section{Introduction}

Central Africa has a rich biodiversity, but there have been few studies of the dynamics, mass balance and regional climatology of this part of the world. Land 
surface temperature (LST) data from remote sensing satellites have been used to study the atmospheric processes in this region, either as a substitute for, or in combination with, more spatially limited ground measurements of the nearsurface air temperature. However, there is a need to improve the assessment and reconstruction of the spatial and temporal variability of the measurements of air temperature at the ground surface recorded by instruments onboard satellites.

Remote sensing technology is a powerful tool to regularly monitor and evaluate the Earth's surface. A major challenge for the scientific community is to ensure that these sensors are correctly calibrated. Post-launch, the onboard instruments are radiometrically calibrated by simulating signals from the surface and the atmosphere based on a single site, which will cause errors between different satellite sensors. The lack of good quality remotely sensed data from different countries and different satellites with multi-source consistency has the potential to limit the scope of remote sensing.

It is therefore important to assess the quality of remote sensing data in Central Africa and to develop a feasible strategy for the quality control of these data (e.g. the AMESD and MESA projects) to ensure the performance of satellites, the quality of the data obtained from them and to guarantee accuracy. This paper reports a comparison of remote sensing data with temperature data measured at ground level to determine whether data from satellites can be used in research work in Central Africa and in the Congo region in particular.

The LST is an important measurement in the global system of data collection by specialized international organizations [1]. LST data have previously been used to improve the quality of prediction in global weather models [2] [3]. The LST is an important parameter in interdisciplinary biological studies, in monitoring ecosystems [4] [5] [6] [7] [8] and in determining the energy balance between the Earth's surface and the atmosphere. The LST is observed by a number of different satellites, each of which is equipped with several different instruments. NASA's Terra satellite is equipped with MODIS (MODerat-resolution Imaging Spectroradiometer), which measures the reflectance of the Earth in 36 spectral bands at a medium spatial resolution and has been designed to monitor medium- and large-scale processes. EUMETSAT's Meterosat Second Generation (MSG) satellite is equipped with the SEVIRI (Spinning Enhanced Visible and Infrared Imager) sensor and transmits a scene recorded in 12 channels of visible, mid-infrared and thermal infrared every 15 minutes with increased spatial resolution [9]. This study used LST data from the MSG and MODIS Terra satellites.

A number of studies have validated the algorithms for the MODIS LST products, taking into account the influence of meteorological parameters such as wind speed and air temperature, the zenith angle of the sensor view [10] [11], the radiometric resolution and the calibration in several thermal infrared bands. The LST products have been used to analyze land use [12] [13] and land cover [14] [15] [16] and the thermal imager has been used to forecast freezing conditions [17]. 
Satellite technology based on imaging in the thermal infrared region presents an opportunity to measure ground temperatures at different spatial and temporal scales for use in in-depth studies of biological, hydrological and climatological ecological systems and in the identification of surface-atmosphere interactions and feedbacks [18] [19] [20] [21].

The Congo-Brazzaville district is important in terms of climate change and agriculture, but is almost inaccessible, which makes conventional meteorological observations on the ground very difficult. Although satellite can provide remote sensing data, these data are difficult to verify as a result of the lack of in situ observations. This study compared the available ground surface data from meteorological measuring stations with data from the satellite products to calibrate the satellite data for use in future studies on climate change.

The aim of this study was to assess the performance of the MODIS LST product aboard NASA's Terra satellite and the LSF edge onboard the MSG satellite to characterize the spatio-temporal variations in the LST over a six-year period from 2009 to 2014. To achieve this, the MODIS and MSG data were compared with the surface temperature measured at meteorological stations in CongoBrazzaville.

This study first determined the number of days on which these two satellites made observations over Central Africa, which corresponds to the number of days with clear skies. The daily and annual temporal distributions of the LST were compared using statistical analysis. The LST behavior was then analyzed with the inclusion of climatic factors.

This paper is structured as follows. Section 2 describes the study area, data and methodology. Section 3 presents the results and their interpretation based on our analysis. Conclusions and recommendations drawn from our findings are outlined in Section 4.

\section{Materials and Methods}

\subsection{Data and Study Area}

\subsubsection{Data}

Two kinds of data were used: 1) satellite image products from MODIS and MSG (Table 1); and 2) in situ data from ground weather stations (Table 2).

The meteorological data were obtained from synoptic stations located throughout the country, covering the whole geographical area of Congo-Brazzaville (Figure 1, Table 2). All of the stations are located in open spaces covered by lawns. The air temperature was measured under cover at $1.5 \mathrm{~m}$ above ground level at 1-h intervals. The data were obtained from the Directorate of Meteorology of Congo-Brazzaville. The temperature data were collected during the synoptic hours, but we focus on here on the data coinciding with the times of satellite overpass.

The NASA's Terra and Aqua satellites began operational observations using MODIS on 24 February 2000 and 4 May 2002, respectively, and the daily observation 
Table 1. Satellite image products used in the study.

\begin{tabular}{ccc}
\hline Satellite & Period & Format \\
\hline Terra MODIS & $2009-2014$ & hdf \\
MSG & $2009-2014$ & hdf \\
\hline
\end{tabular}

Table 2. Meteorological stations by climate type in the Congo-Brazzaville.

\begin{tabular}{ccccc}
\hline Meteorological station & Latitude & Longitude & Altitude $(\mathrm{m})$ & Type of climate \\
\hline Souanké & $2^{\circ} 04^{\prime} 48^{\prime \prime} \mathrm{N}$ & $14^{\circ} 07^{\prime} 48^{\prime \prime} \mathrm{E}$ & 549 & \\
Ouesso & $1^{\circ} 36^{\prime} 48^{\prime \prime} \mathrm{N}$ & $16^{\circ} 03^{\prime} 06^{\prime \prime} \mathrm{E}$ & 352 & Equatorial \\
Impfondo & $1^{\circ} 38^{\prime} 17^{\prime \prime} \mathrm{N}$ & $18^{\circ} 04^{\prime} 00^{\prime \prime} \mathrm{E}$ & 335 & \\
Makoua & $0^{\circ} 00^{\prime} 24^{\prime \prime} \mathrm{N}$ & $15^{\circ} 37^{\prime} 59^{\prime \prime} \mathrm{E}$ & 394 & \\
Kelle & $0^{\circ} 06^{\prime} 00^{\prime \prime} \mathrm{S}$ & $14^{\circ} 29^{\prime} 00^{\prime \prime} \mathrm{E}$ & 408 & \\
Mpouya & $0^{\circ} 53^{\prime} 01^{\prime \prime} \mathrm{S}$ & $14^{\circ} 48^{\prime} 15^{\prime \prime} \mathrm{E}$ & 311 & \\
Gamboma & $1^{\circ} 52^{\prime} 35^{\prime \prime} \mathrm{S}$ & $15^{\circ} 51^{\prime} 51^{\prime \prime} \mathrm{E}$ & 476 & Subequatorial \\
Djambala & $2^{\circ} 32^{\prime} 40^{\prime \prime} \mathrm{S}$ & $14^{\circ} 45^{\prime} 11^{\prime \prime} \mathrm{E}$ & 791 & \\
Ewo & $0^{\circ} 52^{\prime} 00^{\prime \prime} \mathrm{S}$ & $14^{\circ} 49^{\prime} 00^{\prime \prime} \mathrm{E}$ & 438 & \\
Makabana & $3^{\circ} 29^{\prime} 00^{\prime \prime} \mathrm{S}$ & $12^{\circ} 37^{\prime} 00^{\prime \prime} \mathrm{E}$ & 161 & \\
Dolisie & $4^{\circ} 11^{\prime} 54^{\prime \prime} \mathrm{S}$ & $12^{\circ} 39^{\prime} 59^{\prime \prime} \mathrm{E}$ & 329 & \\
Sibiti & $3^{\circ} 40^{\prime} 54^{\prime \prime} \mathrm{S}$ & $13^{\circ} 20^{\prime} 59^{\prime \prime} \mathrm{E}$ & 530 & \\
Mouyondzi & $3^{\circ} 59^{\prime} 32^{\prime \prime} \mathrm{S}$ & $13^{\circ} 55^{\prime} 44^{\prime \prime} \mathrm{E}$ & 509 & \\
Brazzaville & $4^{\circ} 15^{\prime} 56^{\prime \prime S}$ & $15^{\circ} 16^{\prime} 59^{\prime \prime} \mathrm{E}$ & 319 & \\
Pointe-noire & $4^{\circ} 46^{\prime} 33^{\prime \prime} \mathrm{S}$ & $11^{\circ} 51^{\prime} 48^{\prime \prime} \mathrm{E}$ & 17 & \\
Nkayi & $4^{\circ} 18^{\prime} 00^{\prime \prime} \mathrm{S}$ & $13^{\circ} 28^{\prime} 00^{\prime \prime} \mathrm{E}$ & 173 & \\
\hline & & & & \\
\hline
\end{tabular}

times were set at local times of about 01:30, 10:30, 13:30 and 22:30 h. We used the LST product MOD11C1, which is derived from MOD11B1 in bands 31 $(10.78-11.28 \mu \mathrm{m})$ and $32(11.77-12.27 \mu \mathrm{m})$ The dataset is available in hierarchical data format (HDF) at https://lpdaac.usgs.gov.

The MSG is a geostationary satellite covering Europe, Africa, and parts of the Atlantic and Indian oceans. It provides images at 15-min intervals [22]. The LST MSG data were recovered in the 10.8 and $12.0 \mu \mathrm{m}$ thermal infrared spectral bands using the generalized split-window algorithm, which corrects for atmospheric effects on the basis of differential absorption in two adjacent infrared bands [23] [24] [25] [26] [27]. The dataset is also available in HDF at https://landsaf.ipma.pt.

\subsubsection{Study Area}

Congo-Brazzaville (Figure 1) covers $342,000 \mathrm{~km}^{2}$ and is located in Central Africa between $\left(3^{\circ} 30^{\prime} \mathrm{N}\right.$ and $\left.5^{\circ} \mathrm{S}\right)$ and $\left(11\right.$ and $\left.18^{\circ} \mathrm{E}\right)$. It is bordered to the west by Gabon, to the northeast by Cameroon, to the north by the Central African Republic, to the east and southeast by the Democratic Republic of Congo, and to 


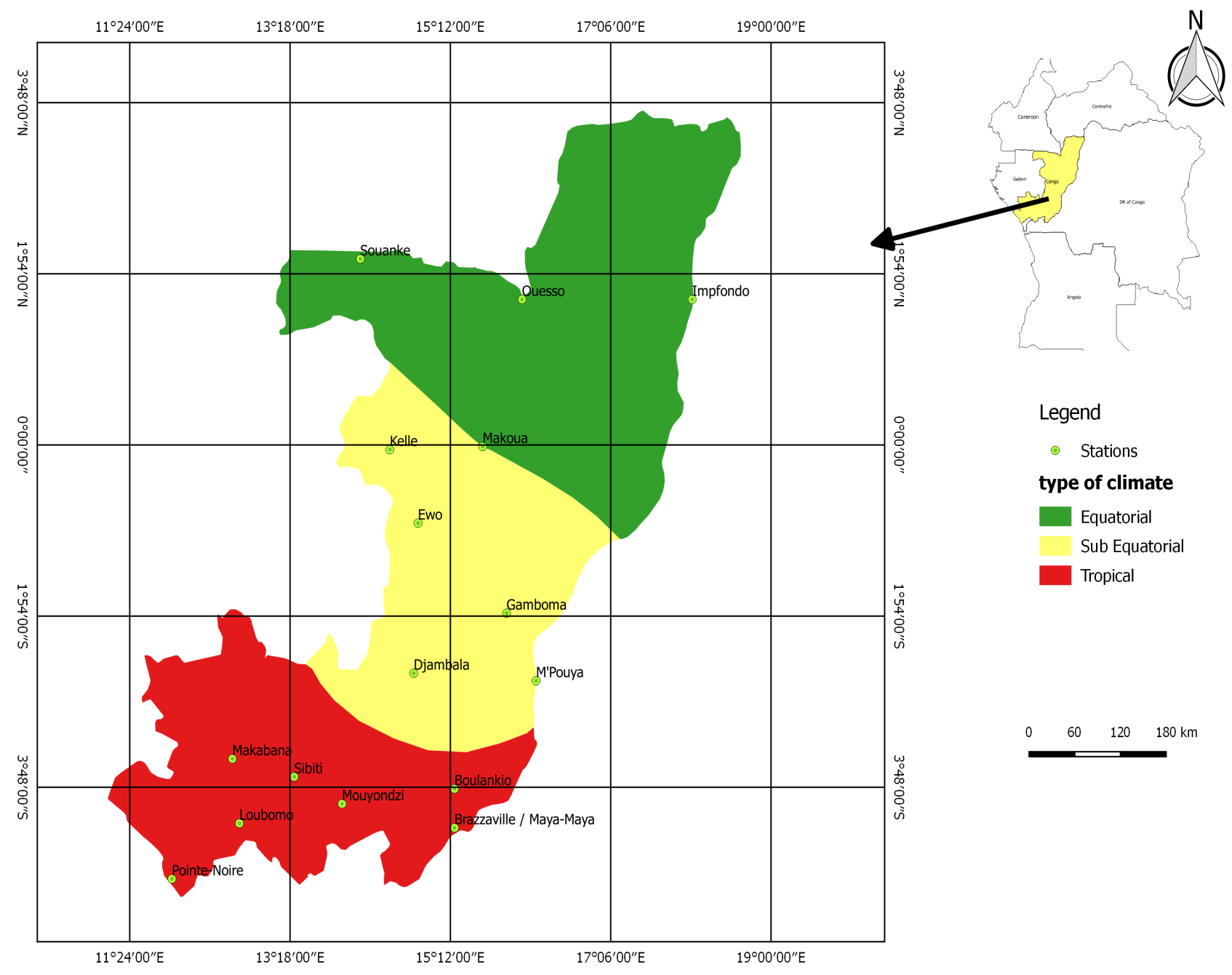

Figure 1. Map of the Congo-Brazzaville showing the types of climate and the locations of weather stations (reproduced from the Atlas du Congo (2001), 2 edn).

the south by the Angolan enclave of Cabinda.

Congo-Brazzaville consists entirely of ancient basement rocks, which outcrop throughout the south of the country. In the north, they are covered by a thick layer of sedimentary rocks, which are most widespread in Batéké and the Congolese Cuvette.

The soils of Congo-Brazzaville are classified as ferralitic soils. Two types of vegetation cover the entire territory-forest and savanna-with a dominance of forest (60\% coverage) [28].

There are three types of climate in Congo-Brazzaville. The climate in the north of the country is equatorial with high humidity. In the center, the climate is subequatorial and is strongly influenced by areas of intertropical low pressure from October to May and southern subtropical high pressure from June to September. The average annual temperature is about $23^{\circ} \mathrm{C}$. The climate in the southwest is humid tropical with monthly average temperatures between $21^{\circ} \mathrm{C}$ and $27^{\circ} \mathrm{C}$ [29] [30]. 


\subsection{Methodology}

Data derived from the satellite LST products were downloaded from Landsaf.ipma.pt for the MSG data and lpdaac.usgs.gov for the MODIS Terra data. The data for each day at the time of passage of the satellite over Congo-Brazzaville were stored in two separate data folders for the analysis period 2009-2014. The data files were extracted to provide time series by hour, day and year [31]. To reduce the time required to read and analyze these data, Matlab and ENVI were used to write processing codes.

The codes were intended: 1 ) to read HDF files to re-projection; 2 ) to resize the data according to the study area; and 3) to extract the values of each pixel based on the geographical coordinates of each station to generate a file of the time series for the data. The time series were limited to the available observations of the satellites, which were limited by the presence of clouds. Another code was written to match the dates of the LST time series with the in situ data for each station. We numerized the in situ data and used a regression method to determine the correlation coefficient between the MODIS and MSG data and the in situ data. The number of cloudless days is defined by Equation (1):

$$
\text { Percentage number of data cloudless days }=\frac{N_{C d}}{N_{Y}} * 100 \%
$$

where $N_{C d}$ is the number of data points for cloudless days and $N_{Y}$ is the number of days per year.

To determine the relationship between the MODIS and MSG LST data and the in situ data, we used the Pearson correlation coefficient $(r)$ and the root mean square error (RMSE). These values show the strength of the link (positive or negative) between the variables. According to the regression model, the $r$ correlation determines a dimensionless scale in the range 0 - 1 and can be expressed as a percentage. The RMSE statistic (Equation (2)) [32] was used to assess the level of agreement between the observed and estimated temperatures for each site. Statistical analysis was conducted using the Originlab statistical software package.

$$
R M S E=\left(\frac{1}{n} \sum_{i=1}^{n}\left(T_{L S T}-T_{O b s}\right)^{2}\right)^{1 / 2}
$$

\section{Results and Discussion}

\subsection{Determination of the Number of Cloudless Days}

Figure 2 shows the percentage of LST measurements obtained from the MODIS and MSG satellites each year from 2009 to 2014 . These values correspond to the days when the sky was clear and the satellites were able to make measurements. The satellite data were not generated continuously because the cloud cover in this region may last for several consecutive days. Congo-Brazzaville is located in an area where there may be persistent cloud coverage of $100 \%$ - for example, for the Pointe-Noire station, over the six years studied, LST measurements were 

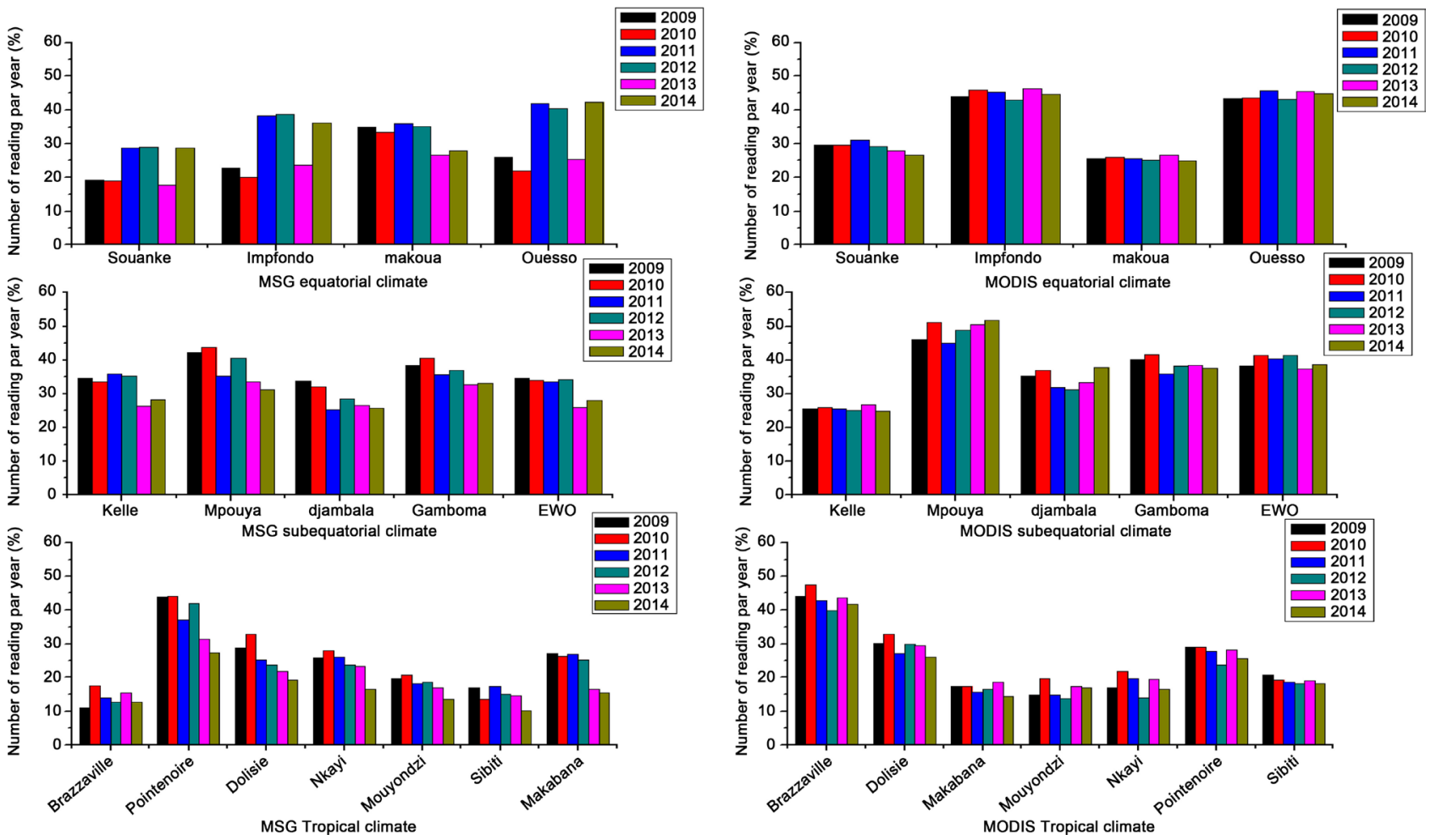

Figure 2. Annual percentage of days on which LST measurements were made by the MSG and MODIS satellites from 2009 to 2014 by climate type.

only possible on an average of $37.5 \%$ days. The lowest average was at Brazzaville station, where measurements by the MSG satellite were made on only $13.8 \%$ of days. These stations are located in the tropical humid climate zone. The LST MODIS data also show that stations in the tropical climate zone have lower percentages of measurements per year compared with stations in other climatic zones, with the average over six years varying between $48.86 \%$ and $18.9 \%$. The highest percentage of measurements per year was obtained at Mpouya station (51.78\%), located in the subequatorial climate zone, and the lowest at the Mouyondzi station (13.7\%), located in the tropical humid climate zone. The low percentage of LST values is explained by deficiencies in the split windows temperature extraction method [33]. Cloud contamination remains a major problem for LST data [34] [35].

The six-year average percentage of days with measurements for each climatic zone indicates that the subequatorial climate zone (average 33.3\% for MSG and $37.4 \%$ for MODIS) has the fewest clouds, whereas the equatorial climatic zone (average $29.73 \%$ for MSG and $35.9 \%$ for MODIS) has the most clouds. The tropical climate zone has an average percentage of days with measurements of 22.2\% for MSG and 24.2\% for MODIS.

The cloud cover data retrieved from the ECMWF analyses (Figure 3) show the proportion of low and high level clouds averaged for each month between 2009 and 2014 and illustrates the extent of cloud cover in this region. The presence of low clouds toward southeast Congo-Brazzaville between January and 

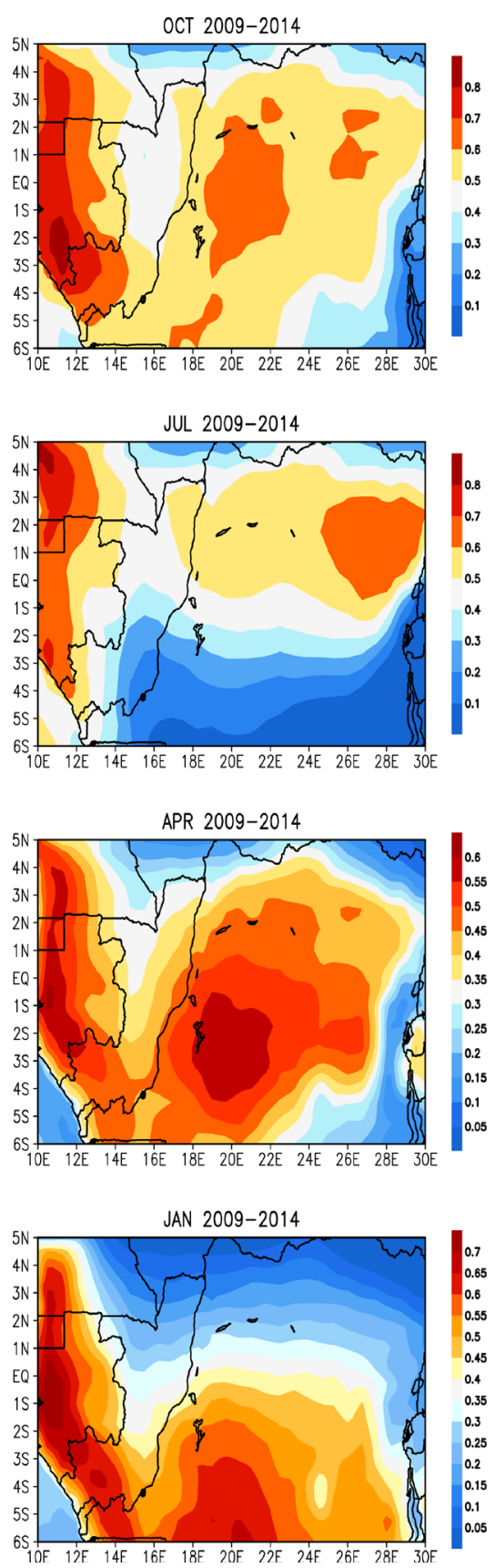

September characterizes the dry season. The maximum cloud cover is located along the Gulf of Guinea coast.

The relative humidity gives the level of saturation of water vapor in the lower troposphere (between 700 and $850 \mathrm{hPa}$ ). A high relative humidity is an indicator of possible cloud formation and precipitation and strongly affects visibility in the atmosphere by influencing the height of clouds and the formation of fog.

Figure 4 shows that the average relative humidity at $700 \mathrm{hPa}$ in the period 2009-2014 was $>70 \%$ throughout the year. The humidity at $850 \mathrm{hPa}$ varied between $80 \%$ and $100 \%$. This high relative humidity is the consequence of the regular humid trade winds and Atlantic monsoon in this part of the world. Their
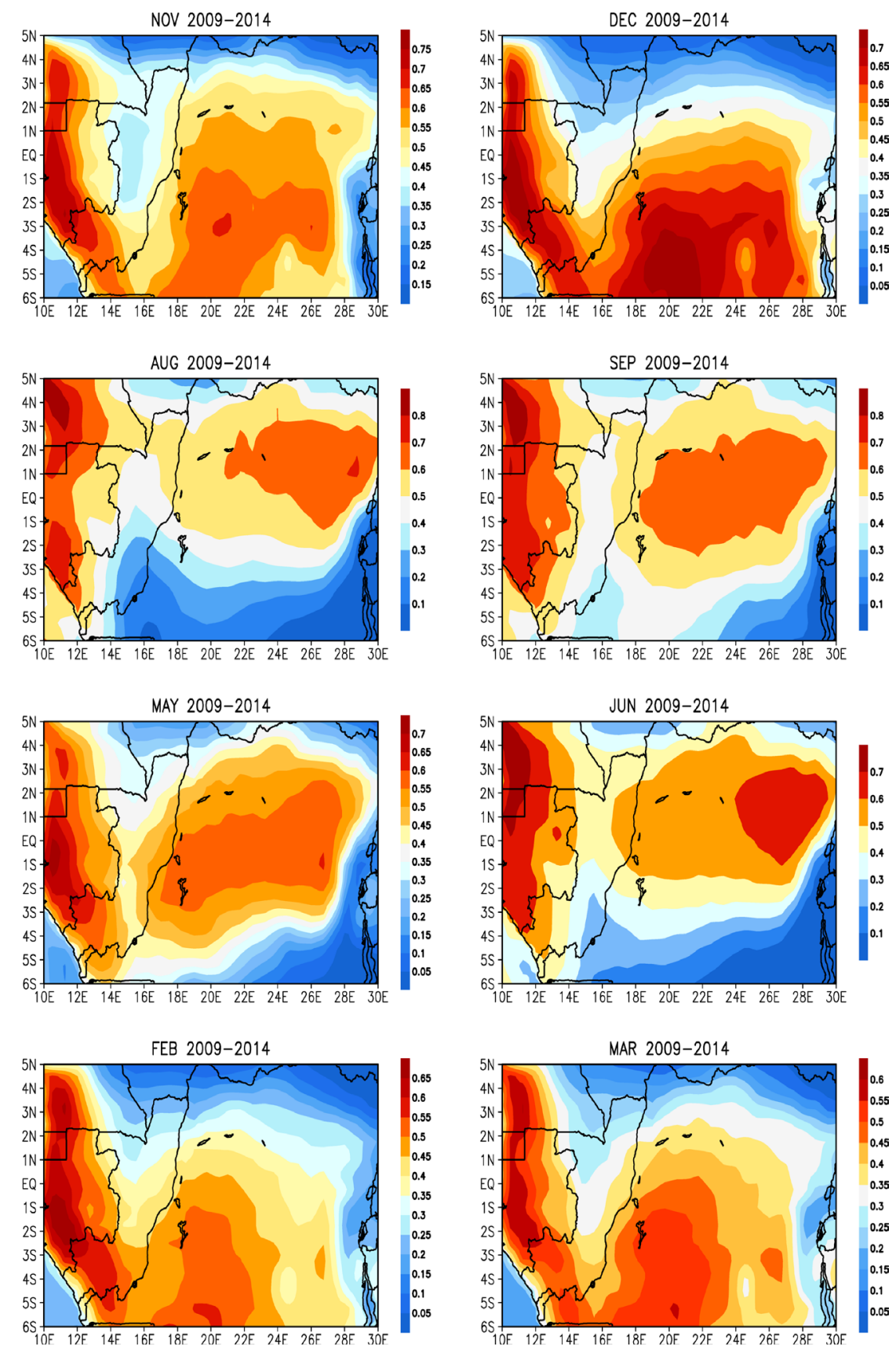

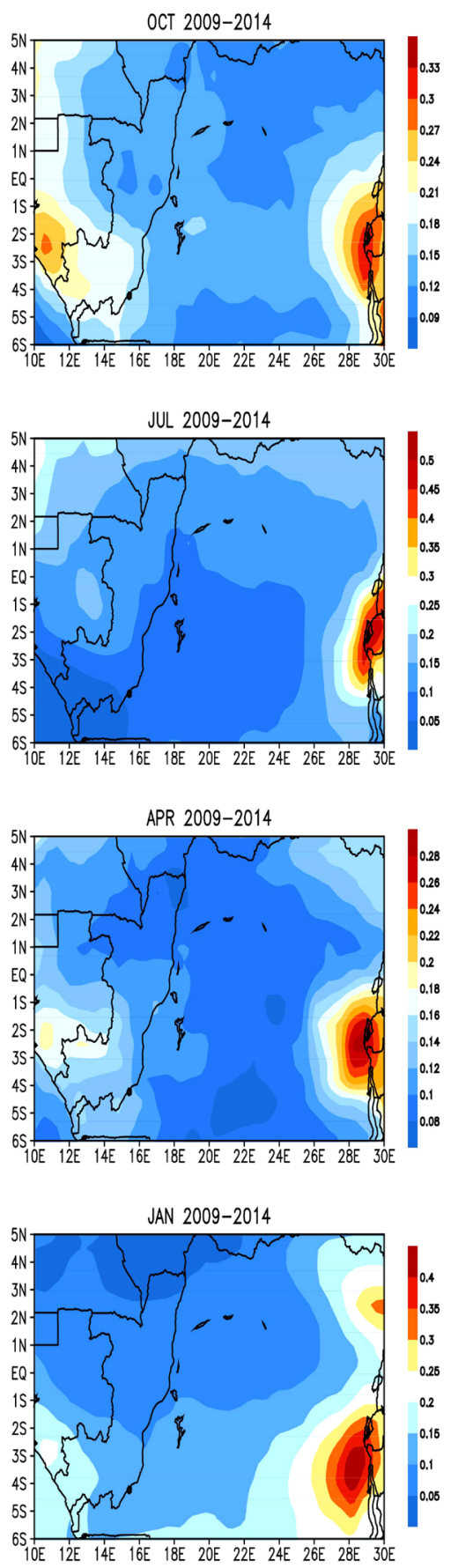
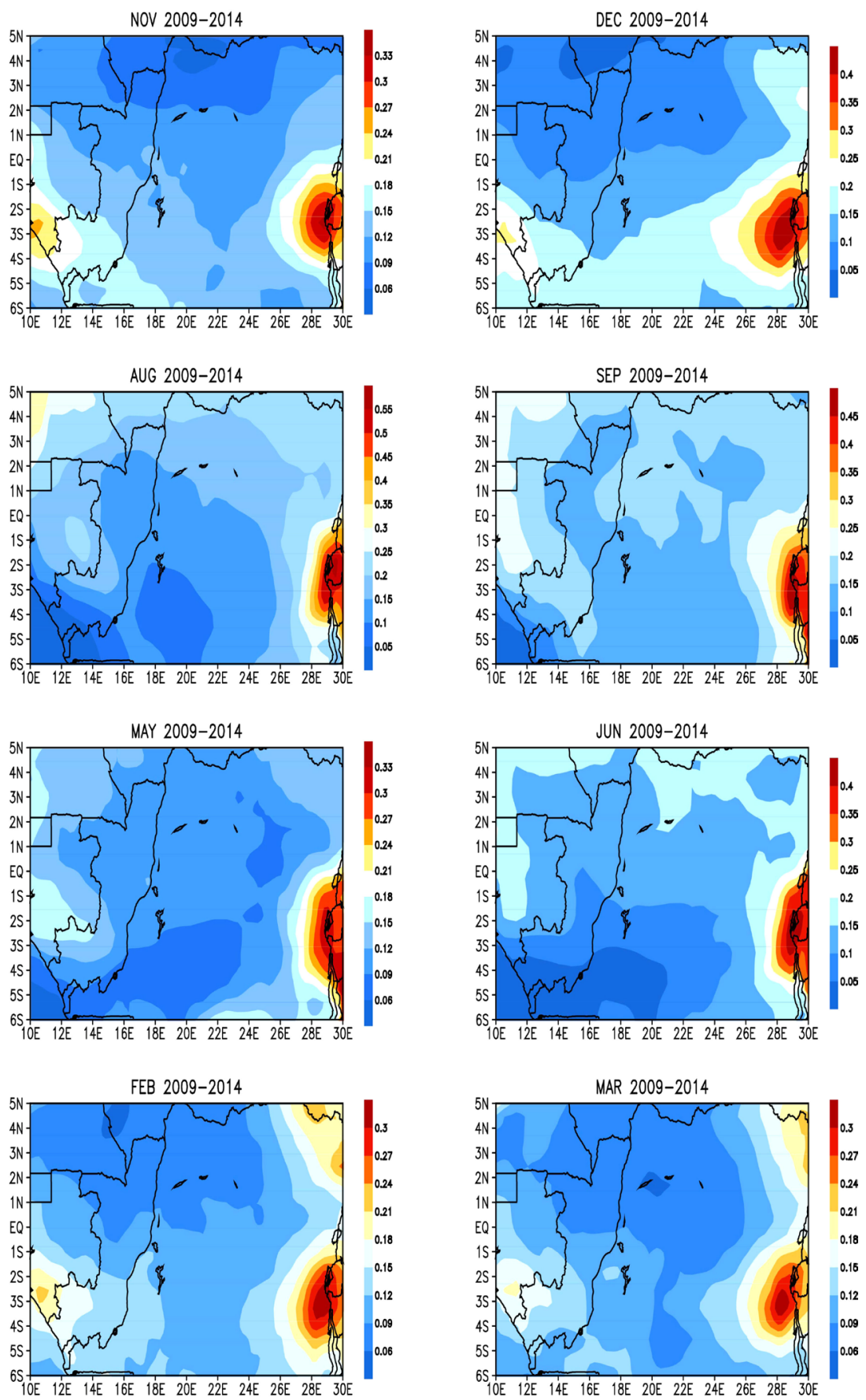

Figure 3. Average monthly cloud cover from 2009 to 2014 for low and medium level clouds.

influence is locally accentuated by the extensive forest cover and the large number of lakes, rivers and wetlands [36]. Toward the southeast (Brazzaville) at 700 $\mathrm{hPa}$, the relative humidity varies between 60 and $80 \%$ and extends to the southwest (Pointe-Noire). This corresponds to the dry season in the southern hemisphere in June-September. At $850 \mathrm{hPa}$ in the northern hemisphere, the average relative humidity varies between 70 and $80 \%$ from November to July. When the relative humidity at the surface increases, the clouds change from shallow to 
deep convective types as a result of an increase in the available potential energy [37] [38].

The results shown in Figure 3 and Figure 4 confirm that the presence of cloud cover over the Congo-Brazzaville is responsible for the low number of daily satellites observations shown in Figure 2.

Figure 5 shows the annual cycle in the variation in temperature between the air temperature measured at the ground stations and the LST product from the MSG and MODIS satellites. During the period June-September, corresponding to the dry season, the temperatures generally decreased (e.g. at the Gamboma Brazzaville and Pointe-Noire stations). By contrast, the seasonal variations were
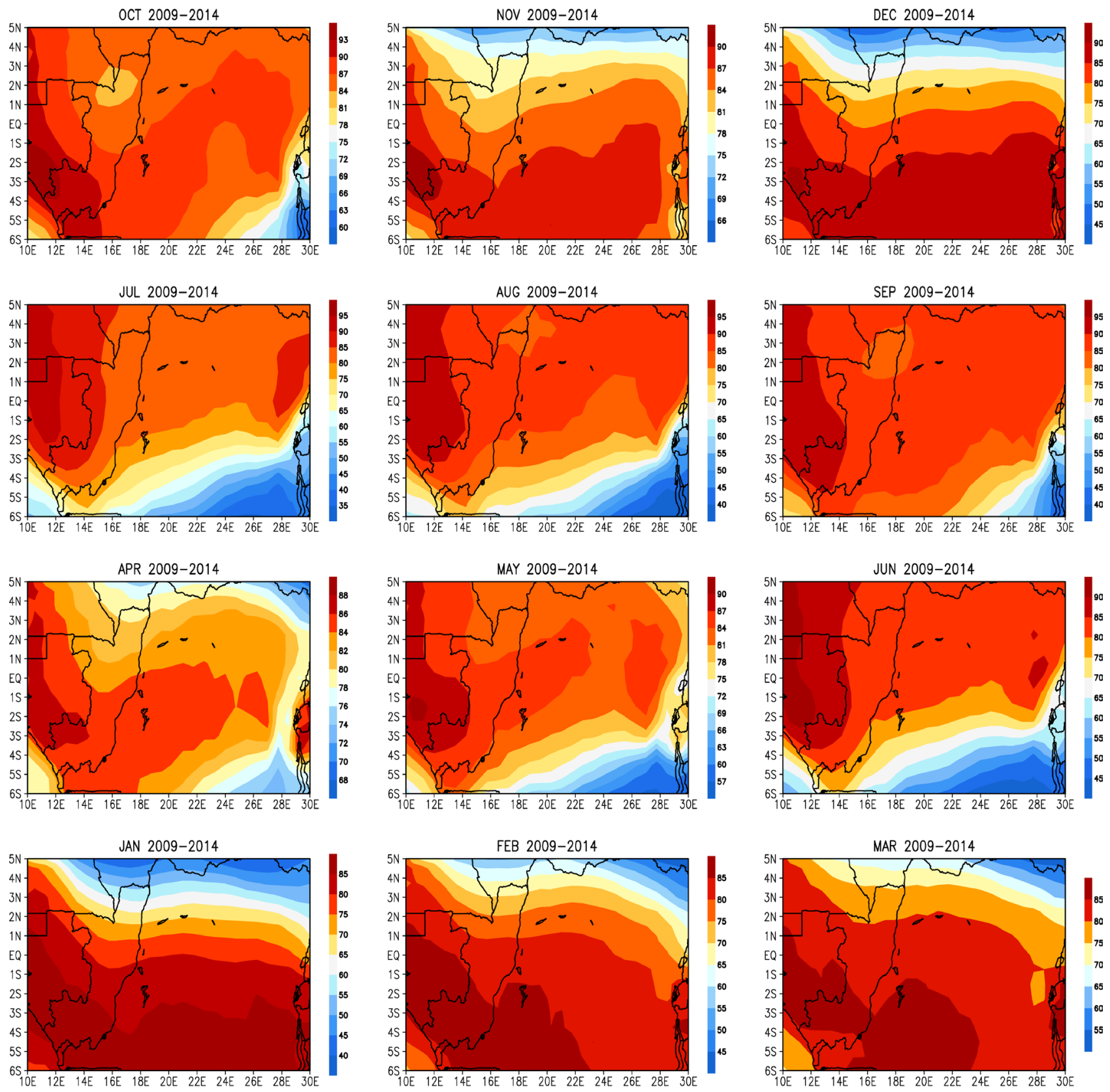

(a) 

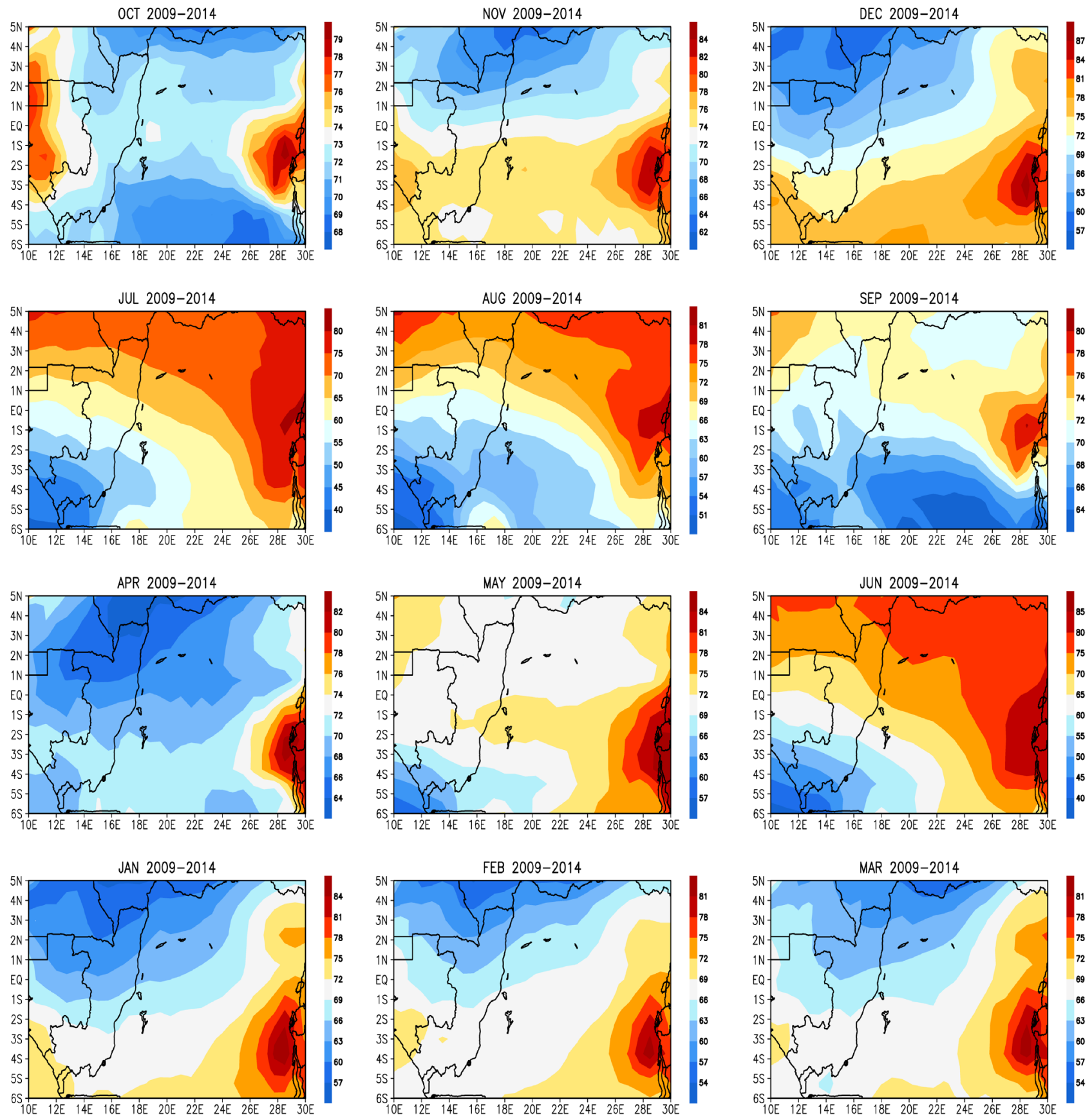

(b)

Figure 4. Average monthly relative humidity at (a) 850 and (b) $700 \mathrm{hPa}$.

more moderate [39] in the region with an equatorial climate (e.g. Ouesso station). The differences between the MODIS LST and MSG LST data and the air temperature measured at the ground stations show that data from both sensors are strongly controlled by the frequency of cloud cover [40].

The data from Gamboma station show that the MODIS LST values overestimated the temperature with respect to the air temperature observed at ground level. At Ouesso station, the MODIS LST values underestimated the air temper- 
ature observed at ground level by $0^{\circ} \mathrm{C}-15^{\circ} \mathrm{C}$. At Brazzaville and Pointe-Noire stations, the MODIS LST underestimated the air temperature observed at ground level (Figure 5, upper panels).

The data from Gamboma station show that the MSG LST values overestimated the air temperature observed at ground level, with differences between 0 and $15^{\circ} \mathrm{C}$. At Brazzaville and Ouessos the MSG LST values overestimated the air temperature observed at ground level by between $-5^{\circ} \mathrm{C}$ and $5^{\circ} \mathrm{C}$ with respect to air temperature. Pointe-Noire also shows an overestimation with differences between $-10^{\circ} \mathrm{C}$ and $15^{\circ} \mathrm{C}$ (Figure 5, lower panels).

Data from Pointe-Noire, Makoua, Brazzaville, Gamboma, Mpouya, Djambala and Dolisie stations show that the MSG LST values overestimated the air temperature observed at ground level with a mean bias between $1.6607^{\circ} \mathrm{C}$ and $8.87281^{\circ} \mathrm{C}$. At Ouesso and Makabana stations the MSG LST values overestimated the air temperature observed at ground level with a mean bias between $-3.44094^{\circ} \mathrm{C}$ and $-0.56705^{\circ} \mathrm{C}$, respectively (Table 3 ).

The data from Ouesso, Brazzaville, Dajambala and Gamboma stations show

(a)

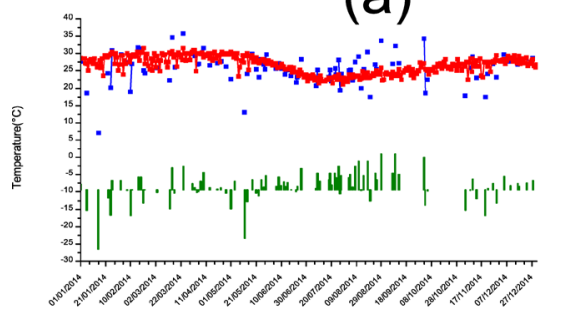

(d)

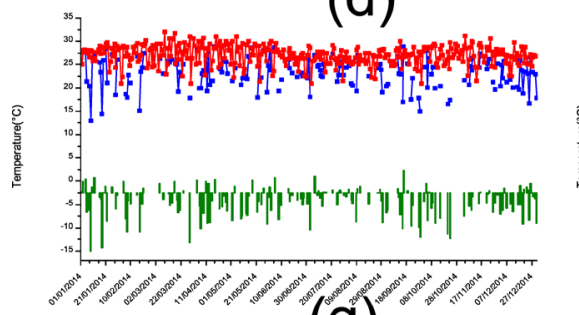

(g)

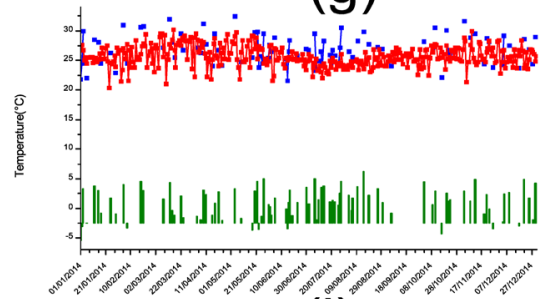

(j)

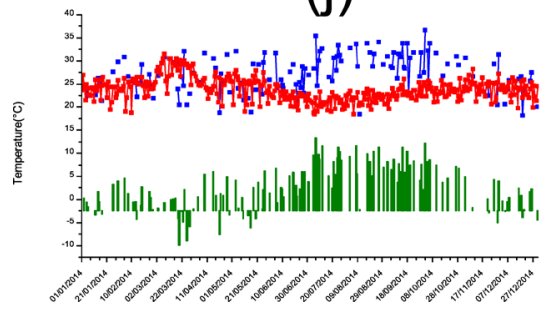

(b)

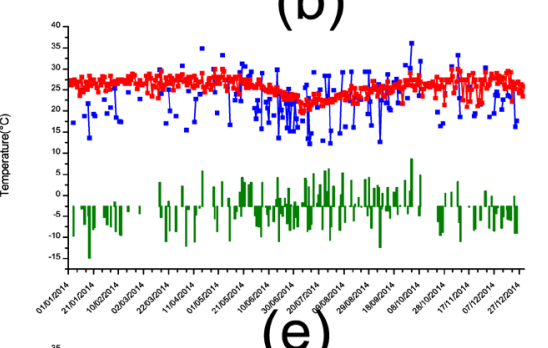

(e)

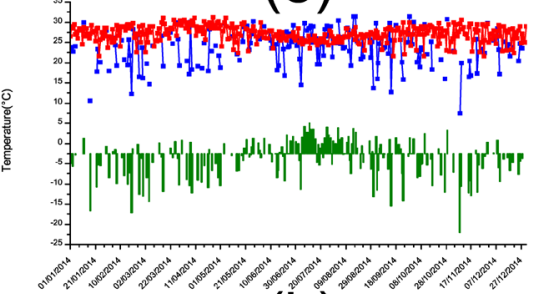

(h)

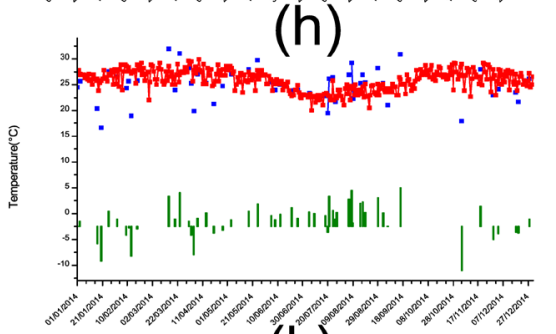

$(\mathrm{k})$

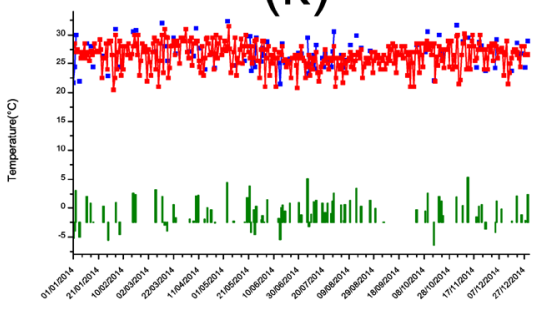

(upper panels) LST from MODIS (c)

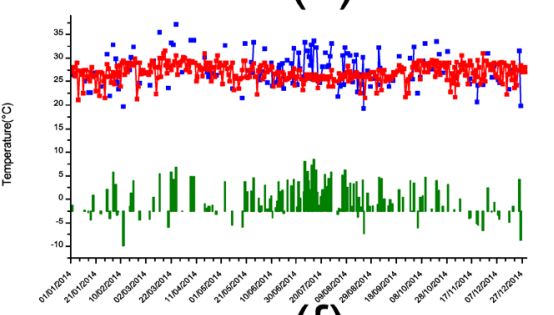

(f).

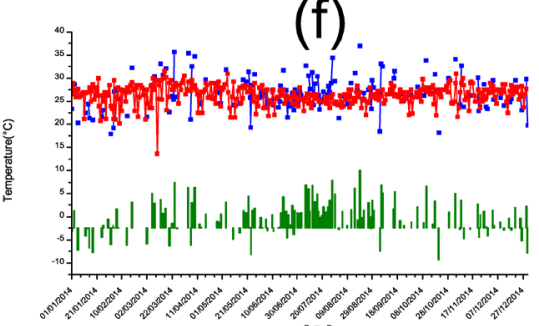

(i)

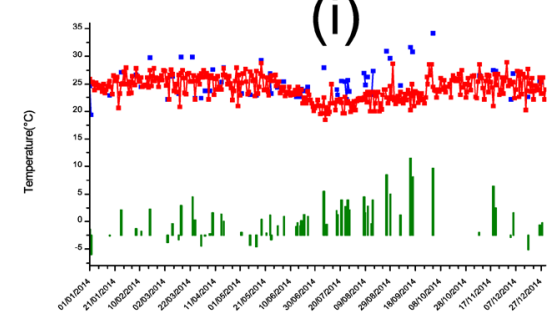


(a)

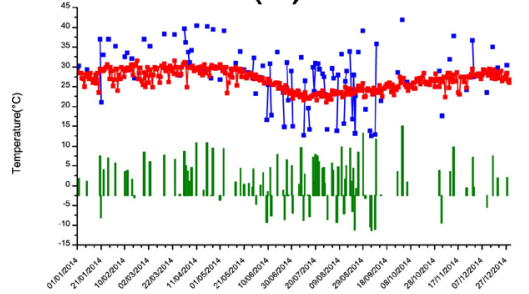

(d)

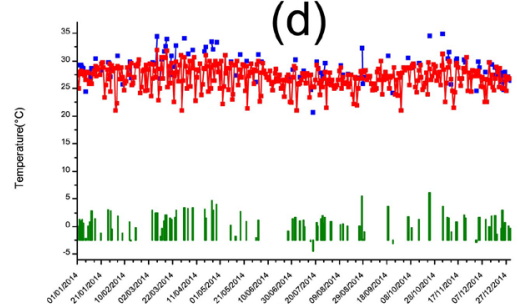

(g)
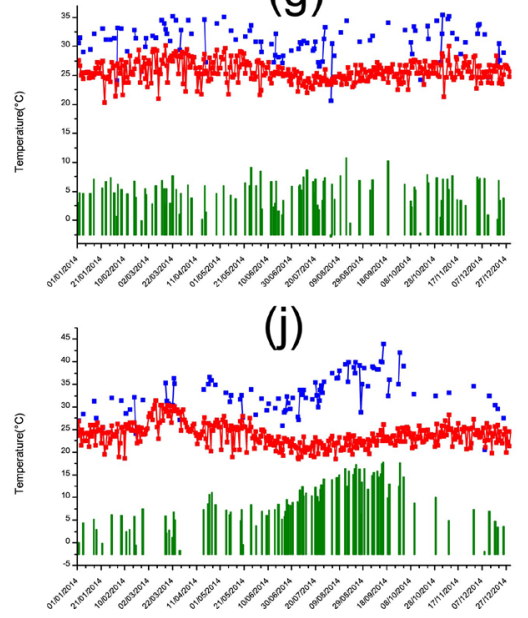

(b)

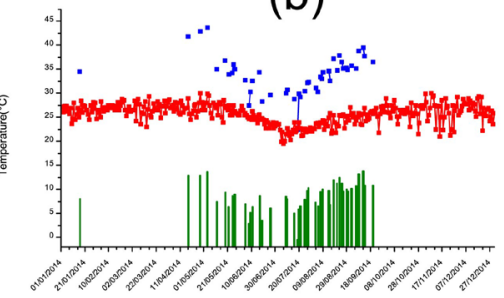

(e)

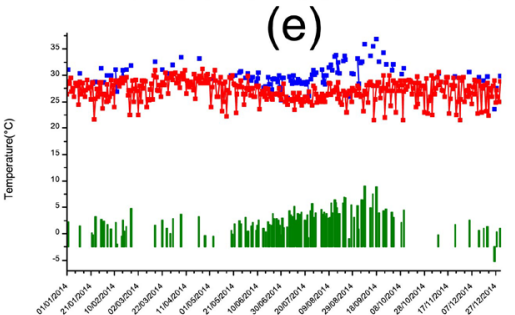

(h)

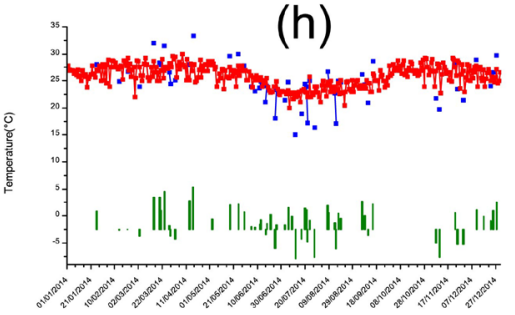

(k)

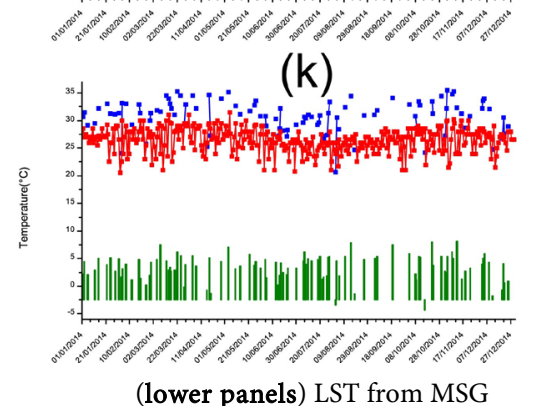

(lower panels) LST from MSG (c)

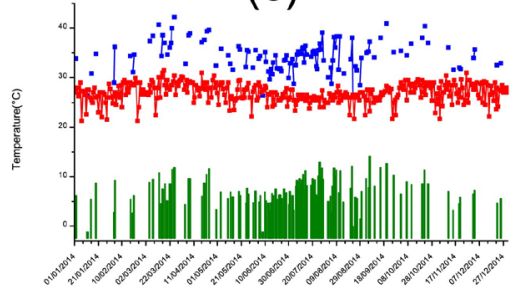

(f)
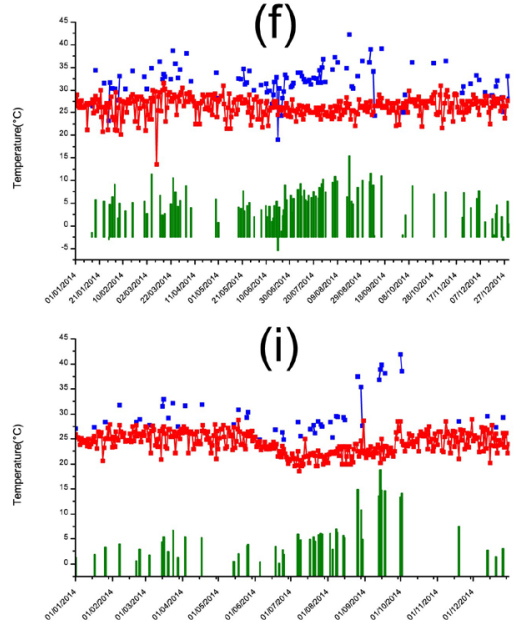

Figure 5. Reconstitution of the times series between the LST data and air temperature for 2014: (a) Pointe-Noire, (b) Brazzaville, (c) Gamboma, (d) Ouesso, (e) Mpouya, (f) Ewo, (g) Kelle, (h) Makabana, (i) Mouyondzi, (j) Djambala and (k) Makoua stations.

that the MODIS LST values overestimated the air temperature observed at ground level with a mean bias between $0.87302^{\circ} \mathrm{C}$ and $4.38296^{\circ} \mathrm{C}$. At Black Peak, Makoua, Mpouya, Makabana and Dolisie stations the MODIS LST values underestimated the air temperature observed at ground level with a mean bias between $-1.01464^{\circ} \mathrm{C}$ and $-1.76591^{\circ} \mathrm{C}$ for the year 2009 .

In general, the values of the MSG LSTs overestimated the observed temperature, whereas the MODIS LST values underestimated the observed temperature (Table 3). These results are in agreement with previously reported work [41].

\subsection{Correlation between the MODIS LST and MSG LST Measurements and the In Situ Air Temperature}

Tables 4-6 show that the stations located in the equatorial climate zone have moderate correlation coefficients of 0.23 for the MSG LST and 0.64 for air temperature. The RMSEs vary between $1.7^{\circ} \mathrm{C}$ and $2.7^{\circ} \mathrm{C}$ and MAEs ranged from $1.6^{\circ} \mathrm{C}$ to $4.66^{\circ} \mathrm{C}$ from 2009 to 2014 . There is a moderate correlation coefficient 
Table 3. Mean difference between the MSG LST air temperature and the MODIS LST air temperatures.

\begin{tabular}{|c|c|c|c|c|c|c|c|c|c|c|c|c|}
\hline \multirow{2}{*}{ Station } & \multicolumn{2}{|c|}{2009} & \multicolumn{2}{|c|}{2010} & \multicolumn{2}{|c|}{2011} & \multicolumn{2}{|c|}{2012} & \multicolumn{2}{|c|}{2013} & \multicolumn{2}{|c|}{2014} \\
\hline & MSG & MODIS & MSG & MODIS & MSG & MODIS & MSG & MODIS & MSG & MODIS & MSG & MODIS \\
\hline Ouesso & -3.44094 & 0.87302 & - & & 0.80273 & -3.42182 & 0.63081 & -4.15 & 0.95 & -4.05044 & 0.85299 & -3.55078 \\
\hline Makoua & 2.72362 & -1.01464 & 2.88403 & -0.85806 & 3.63535 & -0.4731 & 4.21204 & 0.02815 & 4.66302 & 0.23603 & 3.97242 & -0.21613 \\
\hline Souanké & - & & - & & - & & - & & - & & -1.02026 & -3.33684 \\
\hline Impfondo & - & & 1.76147 & -4.48695 & - & & - & & - & & 0.80537 & -4.01519 \\
\hline Gamboma & 7.32239 & 1.24963 & 6.26196 & 0.03982 & 8.76632 & 2.13415 & 7.51587 & 0.85731 & - & & 7.79176 & 1.23847 \\
\hline Mpouya & 2.34608 & -2.31288 & 2.4484 & -2.24296 & 2.6433 & -2.21268 & - & & 3.09092 & -0.95 & 2.79913 & -1.89577 \\
\hline Djambala & 7.54859 & 4.38296 & 8.22854 & 3.14753 & 8.74611 & 4.39333 & 9.85023 & 5.68818 & 6.85508 & 3.04905 & 9.21218 & 3.90051 \\
\hline Ewo & 4.09906 & -0.04969 & - & & 5.28741 & 1.2869 & 5.20708 & 0.37396 & 5.66636 & 0.76013 & 5.627 & 0.58475 \\
\hline Kelle & 4.25409 & 0.5997 & 3.55722 & -0.24074 & 4.33808 & 0.79269 & 5.42381 & 1.13794 & 6.22968 & 1.8027 & 5.46435 & 1.27581 \\
\hline Pointe-noire & 1.66071 & -1.53881 & 2.02239 & -1.8587 & 2.96366 & -1.51195 & 2.37082 & -0.9511 & 4.17103 & 0.11765 & 3.83035 & -0.49456 \\
\hline Brazzaville & 8.87281 & 0.84813 & 9.22904 & 1.12846 & 8.7122 & 0.40805 & 8.53848 & -0.41303 & 8.91429 & 1.85122 & 8.8465 & 0.763 \\
\hline Nkayi & - & & 4.94377 & 0.2418 & 6.8217 & 2.18574 & 5.33276 & 0.88241 & 5.26277 & 1.49468 & & \\
\hline Makabana & -0.56705 & -1.76591 & 0.66229 & -0.39167 & 0.41595 & -0.19541 & 0.09386 & -1.46636 & -0.07781 & -0.44813 & 0.4448 & 0.1452 \\
\hline Dolisie & 2.70597 & -1.20701 & 3.96203 & -0.72875 & 4.8983 & 0.33679 & 3.26102 & -0.34918 & 3.97625 & 0.45313 & 3.74911 & 0.78911 \\
\hline Sibiti & 1.07054 & -1.94459 & 3.6669 & -0.74103 & 1.85917 & -1.97 & 1.89441 & -1.51706 & 2.80912 & -0.71824 & - & \\
\hline Mouyondzi & 4.34278 & 0.13278 & 7.36956 & 3.35756 & 6.43947 & 1.55684 & 4.26059 & 1.00706 & 5.88628 & 2.03233 & 5.3403 & 1.92818 \\
\hline
\end{tabular}

Table 4. Correlation coefficient $(r)$ and RSME between the LST data and the air temperature in regions with an equatorial climate.

\begin{tabular}{|c|c|c|c|c|c|c|c|c|c|c|c|c|c|c|c|c|c|c|}
\hline \multirow{3}{*}{ Station } & \multicolumn{3}{|c|}{2009} & \multicolumn{3}{|c|}{2010} & \multicolumn{3}{|c|}{2011} & \multicolumn{3}{|c|}{2012} & \multicolumn{3}{|c|}{2013} & \multicolumn{3}{|c|}{2014} \\
\hline & \multicolumn{3}{|c|}{ MSG } & \multicolumn{3}{|c|}{ MSG } & \multicolumn{3}{|c|}{ MSG } & \multicolumn{3}{|c|}{ MSG } & \multicolumn{3}{|c|}{ MSG } & \multicolumn{3}{|c|}{ MSG } \\
\hline & $r$ & MAE & RMSE & $r$ & MAE & RMSE & $r$ & MAE & RMSE & $r$ & MAE & RMSE & $r$ & MAE & RMSE & $r$ & MAE & RMSE \\
\hline Ouesso & 0.27 & 4.2198 & 2.0113 & - & & & 0.42 & 1.8866 & 2.1618 & 0.23 & 1.9137 & 2.2779 & 0.47 & 1.778 & 1.897 & 0.57 & 1.6184 & 1.7874 \\
\hline Makoua & 0.421 & 3.252 & 2.7999 & 0.64 & 3.3202 & 2.6387 & 0.28 & 4.0109 & 2.7451 & 0.576 & 4.308 & 2.3812 & 0.639 & 4.663 & 1.9467 & 0.482 & 4.134 & 2.141 \\
\hline Souanké & - & & & - & & & - & & & - & & & - & & & 0.257 & 2.0966 & 2.237 \\
\hline \multirow[t]{3}{*}{ Impfondo } & - & & & 0.587 & 2.5539 & 2.5145 & - & & & - & & & - & & & 0.442 & 1.8706 & 2.1626 \\
\hline & \multicolumn{3}{|c|}{ MODIS } & \multicolumn{3}{|c|}{ MODIS } & \multicolumn{3}{|c|}{ MODIS } & \multicolumn{3}{|c|}{ MODIS } & \multicolumn{3}{|c|}{ MODIS } & \multicolumn{3}{|c|}{ MODIS } \\
\hline & $r$ & MAE & RMSE & $r$ & MAE & RMSE & $r$ & MAE & RMSE & $r$ & MAE & RMSE & $r$ & MAE & RMSE & $r$ & MAE & RMSE \\
\hline Ouesso & 0.025 & 1.9847 & 3.6412 & - & & & 0.17 & 3.8925 & 3.1334 & 0.246 & 4.4158 & 3.0466 & 0.19 & 4.1673 & 3.2679 & 0.39 & 3.6513 & 2.6555 \\
\hline Makoua & 0.429 & 2.0001 & 2.2853 & 0.64 & 2.056 & 2.4099 & 0.163 & 2.459 & 2.8846 & 0.435 & 2.0493 & 2.371 & 0.595 & 1.8665 & 2.2113 & 0.24 & 2.1442 & 2.562 \\
\hline Souanké & - & & & - & & & - & & & - & & & - & & & 0.252 & 3.4505 & 2.5036 \\
\hline Impfondo & - & & & 0.383 & 4.5863 & 3.0968 & - & & & - & & & - & & & 0.413 & 4.0812 & 2.8897 \\
\hline
\end{tabular}


Table 5. Correlation coefficient $(r)$ and RSME between the LST data and the air temperature in regions with a subequatorial climate.

\begin{tabular}{|c|c|c|c|c|c|c|c|c|c|c|c|c|c|c|c|c|c|c|}
\hline \multirow{3}{*}{ Station } & \multicolumn{3}{|c|}{2009} & \multicolumn{3}{|c|}{2010} & \multicolumn{3}{|c|}{2011} & \multicolumn{3}{|c|}{2012} & \multicolumn{3}{|c|}{2013} & \multicolumn{3}{|c|}{2014} \\
\hline & \multicolumn{3}{|c|}{ MSG } & \multicolumn{3}{|c|}{ MSG } & \multicolumn{3}{|c|}{ MSG } & \multicolumn{3}{|c|}{ MSG } & \multicolumn{3}{|c|}{ MSG } & \multicolumn{3}{|c|}{ MSG } \\
\hline & $r$ & MAE & RMSE & $r$ & MAE & RMSE & $r$ & MAE & RMSE & $r$ & MAE & RMSE & $r$ & MAE & RMSE & $r$ & MAE & RMSE \\
\hline Gamboma & 0.486 & 3.252 & 2.6271 & 0.477 & 6.3539 & 2.9769 & 0.156 & 8.7861 & 3.2467 & 0.265 & 7.5159 & 2.8712 & - & & & 0.414 & 7.8205 & 2.7227 \\
\hline Mpouya & 0.41 & 2.6485 & 2.2268 & 0.33 & 2.9252 & 2.5934 & 0.43 & 2.9744 & 2.461 & - & & & 0.31 & 3.2441 & 2.2392 & 0.3076 & 2.9578 & 2.0013 \\
\hline Djambala & 0.165 & 7.6444 & 3.3217 & 0.073 & 8.2699 & 3.7399 & 0.197 & 8.7461 & 3.7807 & 0.202 & 9.853 & 3.4828 & 0.319 & 6.8551 & 3.5592 & 0.07 & 9.2663 & 3.8801 \\
\hline Ewo & 0.062 & 4.5313 & 3.0823 & - & & & 0.0781 & 5.3967 & 2.9856 & 0.1 & 5.4606 & 3.0693 & 0.33 & 5.6731 & 3.1583 & 0.172 & 5.8218 & 3.20122 \\
\hline \multirow[t]{3}{*}{ Kelle } & 0.39 & 4.548 & 2.8472 & 0.73 & 3.6806 & 2.363 & 0.13 & 4.7142 & 3.1175 & 0.452 & 5.4298 & 2.5218 & 0.487 & 6.2297 & 2.2119 & 0.416 & 5.5353 & 2.2229 \\
\hline & \multicolumn{3}{|c|}{ MODIS } & \multicolumn{3}{|c|}{ MODIS } & \multicolumn{3}{|c|}{ MODIS } & \multicolumn{3}{|c|}{ MODIS } & \multicolumn{3}{|c|}{ MODIS } & \multicolumn{3}{|c|}{ MODIS } \\
\hline & $r$ & MAE & RMSE & $r$ & MAE & RMSE & $r$ & MAE & RMSE & $r$ & MAE & RMSE & $r$ & MAE & RMSE & $r$ & MAE & RMSE \\
\hline Gamboma & 0.389 & 2.6001 & 2.8956 & 0.442 & 2.5364 & 3.185 & 0.018 & 4.3119 & 3.9188 & 0.28 & 2.7596 & 3.3205 & - & & & 0.313 & 3.106 & 3.4836 \\
\hline Mpouya & 0.1 & 3.4844 & 4.1532 & 0.28 & 3.1663 & 3.478 & 0.17 & 3.7533 & 4.2221 & - & & & 0.12 & 3.1495 & 4.078 & 0.01 & 3.0896 & 3.5353 \\
\hline Djambala & 0.01 & 5.292 & 3.7115 & 0.138 & 4.3107 & 4.1273 & 0.159 & 5.0236 & 4.4919 & 0.063 & 6.2882 & 4.5324 & 0.062 & 4.7929 & 3.9122 & 0.24 & 5.1695 & 3.7115 \\
\hline Ewo & 0.05 & 3.5303 & 3.9396 & - & & & 0.057 & 3.2366 & 3.5732 & 0.245 & 2.834 & 3.5162 & 0.212 & 2.8749 & 3.3831 & 0.312 & 3.0485 & 3.78699 \\
\hline Kelle & 0.4 & 1.9433 & 2.2875 & 0.53 & 2.2185 & 3.0956 & 0.078 & 2.3846 & 2.5739 & 0.372 & 2.3494 & 2.7394 & 0.43 & 2.4941 & 2.4727 & 0.38 & 2.38 & 2.4434 \\
\hline
\end{tabular}

Table 6. Correlation coefficient $(r)$ and RSME between the LST data and the air temperature in regions with a tropical humid climate.

\begin{tabular}{|c|c|c|c|c|c|c|c|c|c|c|c|c|c|c|c|c|c|c|}
\hline \multirow{3}{*}{ stations } & \multicolumn{3}{|c|}{2009} & \multicolumn{3}{|c|}{2010} & \multicolumn{3}{|c|}{2011} & \multicolumn{3}{|c|}{2012} & \multicolumn{3}{|c|}{2013} & \multicolumn{3}{|c|}{2014} \\
\hline & \multicolumn{3}{|c|}{ MSG } & \multicolumn{3}{|c|}{ MSG } & \multicolumn{3}{|c|}{ MSG } & \multicolumn{3}{|c|}{ MSG } & \multicolumn{3}{|c|}{ MSG } & \multicolumn{3}{|c|}{ MSG } \\
\hline & $r$ & MAE & RMSE & $r$ & MAE & RMSE & $r$ & MAE & RMSE & $r$ & MAE & RMSE & $r$ & MAE & RMSE & $r$ & MAE & RMSE \\
\hline Pointe-noire & 0.518 & 4.2176 & 4.9624 & 0.454 & 5.022 & 5.4611 & 0.402 & 4.7239 & 5.1365 & 0.346 & 4.2626 & 4.5802 & 0.451 & 5.9919 & 5.8166 & 0.499 & 5.0153 & 4.5957 \\
\hline Brazzaville & 0.656 & 8.8728 & 2.7478 & 0.558 & 9.229 & 3.3541 & 0.568 & 8.7122 & 3.76 & 0.464 & 8.5385 & 3.1903 & 0.701 & 8.9143 & 2.4313 & 0.764 & 8.869 & 2.7918 \\
\hline Nkayi & - & & & 0.28 & 5.6939 & 5.5098 & 0.271 & 6.923 & 4.3799 & 0.186 & 5.7762 & 4.1638 & 0.289 & 5.9538 & 5.1563 & & & \\
\hline Makabana & 0.427 & 2.4398 & 3.1874 & 0.315 & 3.2973 & 3.9981 & 0.365 & 2.8987 & 3.4165 & 0.355 & 2.8589 & 3.5649 & 0.229 & 2.6191 & 3.0677 & 0.663 & 1.972 & 2.5194 \\
\hline Dolisie & 0.069 & 4.0606 & 4.2608 & 0.058 & 4.6811 & 4.127 & 0.363 & 5.2938 & 4.5223 & 0.187 & 4.7688 & 4.536 & 0.199 & 4.2538 & 3.3501 & 0.384 & 4.0776 & 3.5275 \\
\hline Sibiti & 0.049 & 3.6424 & 3.7387 & 0.313 & 4.1159 & 3.7302 & 0.368 & 3.3286 & 3.2163 & 0.389 & 3.2374 & 3.2219 & 0.683 & 3.2232 & 2.6256 & - & & \\
\hline \multirow[t]{3}{*}{ Mouyondzi } & 0.283 & 4.8972 & 3.4305 & 0.028 & 7.4389 & 4.8 & 0.3917 & 6.4558 & 4.7582 & 0.374 & 4.5053 & 2.9436 & 0.443 & 5.9021 & 3.197 & 0.088 & 5.3403 & 3.7409 \\
\hline & \multicolumn{3}{|c|}{ MODIS } & \multicolumn{3}{|c|}{ MODIS } & \multicolumn{3}{|c|}{ MODIS } & \multicolumn{3}{|c|}{ MODIS } & \multicolumn{3}{|c|}{ MODIS } & \multicolumn{3}{|c|}{ MODIS } \\
\hline & $r$ & MAE & RMSE & $r$ & MAE & RMSE & $r$ & MAE & RMSE & $r$ & MAE & RMSE & $r$ & MAE & RMSE & $r$ & MAE & RMSE \\
\hline Pointe-noire & 0.259 & 3.0698 & 3.2189 & 0.208 & 3.3846 & 3.7713 & 0.11 & 3.6237 & 3.4551 & 0.231 & 2.9108 & 3.1278 & 0.161 & 3.3988 & 3.69 & 0.439 & 2.7851 & 3.4529 \\
\hline Brazzaville & 0.188 & 2.7931 & 3.0995 & 0.252 & 3.5296 & 4.1097 & 0.206 & 3.3417 & 3.8145 & 0.155 & 3.5906 & 4.3869 & 0.048 & 4.1235 & 3.7746 & 0.284 & 3.0795 & 3.3453 \\
\hline Nkayi & - & & & 0.224 & 2.9162 & 3.6851 & 0.252 & 3.4666 & 4.0699 & 0.02 & 3.0045 & 3.3729 & 0.142 & 3.7449 & 4.1768 & - & & \\
\hline Makabana & 0.032 & 2.6796 & 2.5621 & 0.0326 & 2.3871 & 2.3884 & 0.018 & 3.103 & 3.4265 & 0.133 & 2.7355 & 2.3191 & 0.093 & 3.12 & 2.7234 & $=0.6$ & 1.802 & 2.3795 \\
\hline Dolisie & 0.076 & 3.2864 & 3.6093 & 0.0701 & 3.4716 & 3.8695 & 0.203 & 2.9711 & 3.9455 & 0.16 & 2.9047 & 3.1488 & 0.002 & 3.1963 & 3.478 & 0.361 & 2.426 & 3.387 \\
\hline Sibiti & 0.123 & 3.8576 & 3.5561 & 0.094 & 3.0548 & 3.4718 & 0.034 & 4.1744 & 3.8194 & 0.166 & 2.5135 & 2.4852 & 0.48 & 2.2147 & 2.0698 & - & & \\
\hline Mouyondzi & 0.134 & 2.4194 & 2.9246 & 0.048 & 4.2647 & 3.1404 & 0.344 & 3.0674 & 3.6893 & 0.447 & 2.1512 & 2.3464 & 0.329 & 3.1128 & 2.872 & 0.029 & 3.2367 & 3.157 \\
\hline
\end{tabular}


between the MODIS LST and air temperature, except for Ouesso station, which has low correlation coefficients ( $r=0.025$ in 2009, $r=0.17$ in 2011). The RMSEs vary between $2^{\circ} \mathrm{C}$ and $3.5^{\circ} \mathrm{C}$ and the MAEs range from $1.8^{\circ} \mathrm{C}$ to $4.6^{\circ} \mathrm{C}$. We found that Ouesso station showed better accuracy between the MSG LST and air temperature between 2011 and 2014, with the RMSE and MAE values decreasing to $1.7^{\circ} \mathrm{C}$ and $1.6^{\circ} \mathrm{C}$, respectively. Using the MODIS LST data during the same period, we obtained a better accuracy only at Makoua station (RMSE $=2.2, r=0.59$ and MAE $=1.86$ ). A previously reported study using MODIS data over the corn belt of the USA [42] obtained an RMSE value of 4.24 and an MAE of 3.29 and used these data to estimate the daily air temperature.

The stations located in the area of subequatorial climate showed moderate correlation coefficients between the MSG LST and the air temperature measured at ground level, varying between 0.25 and 0.487 , with the exception of the Ewo and Djambala stations with correlation coefficients between 0.062 and 0.20 . The correlation coefficients between MODIS LST and the air temperature measured at ground level are very low (between 0.05 and 0.28), with the exception of Kelle station, which showed moderate values between 0.4 and 0.58 . The RMSE between the MSG LST and the air temperature measured at ground level varied between $2^{\circ} \mathrm{C}$ and $3.88^{\circ} \mathrm{C}$ and those of MAE between $2.64^{\circ} \mathrm{C}$ and $9.26^{\circ} \mathrm{C}$. Similar results for MAE in West Africa have been reported previously [43]. The RMSE values between the MODIS LST data and the air temperature measured at ground level range from $2.49^{\circ} \mathrm{C}$ to $4.53^{\circ} \mathrm{C}$ and those from MAE range from $1.94^{\circ} \mathrm{C}$ to $5.02^{\circ} \mathrm{C}$. The MSG LST data did not give better accuracy, with the exception of Kelle station, where the correlation coefficient $r=0.73$, RMSE $=$ $2.36^{\circ} \mathrm{C}$ and $\mathrm{MAE}=3.68^{\circ} \mathrm{C}$ in 2010 . A better accuracy was obtained with the MODIS LST data, with RMSE $=2.28^{\circ} \mathrm{C}, \mathrm{MAE}=1.94^{\circ} \mathrm{C}$ and $r=0.4$ in 2009.

The stations located in the area with a humid tropical climate were identical to those in the subtropical zone, with the exception of Brazzaville station, which had a correlation coefficient $>0.5$ between 2009 and 2014, Pointe-Noire station with a correlation coefficient of 0.51 in 2009, and Makabana station with a correlation coefficient of 0.663 , RMSE $=2.5^{\circ} \mathrm{C}$ and $\mathrm{MAE}=1.97^{\circ} \mathrm{C}$ in 2014. A better accuracy was observed between the MSG LST and the air temperature measured at ground level. There was a better accuracy between the MODIS LST and the air temperature measured at ground level in 2014 than in other years.

\section{Conclusions}

We carried out a comparative study between the data obtained from the MSG and MODIS LST products and the air temperature data measured at ground level to determine whether these satellite data are suitable for use in research work in Central Africa. There is currently little published climate data available for this part of Africa.

The MSG LSTs showed a moderate correlation with air temperature measurements at $2 \mathrm{~m}$ above ground level at meteorological ground stations in the 
equatorial climate zone and good accuracy at some of the stations in the area. The MODIS LST data also showed good precision at some stations, especially those located in zones characterized by a subequatorial climate or humid tropical climate. These results corroborate those obtained in previous studies on the validation of satellite data [43] [44] [45].

The air temperature measured by these satellites can be used in future studies of climate change and in high-resolution regional climate models. The small amount of data from the two types of temperature measurement are a result of a number of factors, including temperature inversion, heterogeneities in surface emissivity and self-limiting satellites.

Future work should be carried out to evaluate LST products from other Earth observation satellites and to compare these results with a numerical model for this region.

\section{Acknowledgements}

I thank the World Meteorological Organization and the China/Nanjing University of Information Science \& Technology, who have supported me during my studies and in this research. I acknowledge support from Water Resources Management, the International Commission of the Congo-Ubangi-Sangha Basin, Democratic Republic of Congo, and the Directorate of Meteorology, CongoBrazzaville. This work is supported by the National Natural Science Foundation of China (41675028) and is a Project Funded by the Priority Academic Program Development of Jiangsu Higher Education Institutions.

\section{References}

[1] Llewellyn-Jones, D. and Lengert, W. (2009) Review of Remotely Sensed Land Surface Temperature (LST) Products and Their Applications.

[2] Price, J.C. (1982) On the Use of Satellite Data to Infer Surface Fluxes at Meteorological Scales. Journal of Applied Meteorology, 21, 1111-1122. https://doi.org/10.1175/1520-0450(1982)021<1111:OTUOSD>2.0.CO;2

[3] Diak, G.R. and. Whipple, M.S (1993) Improvements to Models and Methods for Evaluating the Land-Surface Energy Balance and "Effective" Roughness Using Radiosonde Reports and Satellite-Measured "Skin" Temperature Data. Agricultural and Forest Meteorology, 63, 189-218. https://doi.org/10.1016/0168-1923(93)90060-U

[4] Lambin, E.F. and Ehrlich, D. (1997) Land-Cover Changes in Sub-Saharan Africa (1982-1991): Application of a Change Index Based on Remotely Sensed Surface Temperature and Vegetation Indices at a Continental Scale. Remote Sensing of Environment, 61, 181-200. https://doi.org/10.1016/S0034-4257(97)00001-1

[5] Karnieli, A., et al. (2010) Use of NDVI and Land Surface Temperature for Drought Assessment: Merits and Limitations. Journal of Climate, 23, 618-633. https://doi.org/10.1175/2009JCLI2900.1

[6] Weng, Q., Lu, D. and Schubring, J. (2004) Estimation of Land Surface Temperature-Vegetation Abundance Relationship for Urban Heat Island Studies. Remote Sensing of Environment, 89, 467-483. https://doi.org/10.1016/j.rse.2003.11.005 
[7] Jenerette, G.D., Harlan, S.L., Brazel, A., Jones, N., Larsen, L. and Stefanov, W.L. (2007) Regional Relationships between Surface Temperature, Vegetation, and $\mathrm{Hu}$ man Settlement in a Rapidly Urbanizing Ecosystem. Landscape Ecology, 22, 353-365.

[8] Mingwei, Z., Qingbo, Z., Zhongxin, C., Jia, L., Yong, Z. and Chongfa, C. (2008) Crop Discrimination in Northern China with Double Cropping Systems Using Fourier Analysis of Time-Series MODIS Data. International Journal of Applied Earth Observation and Geoinformation, 10, 476-485.

https://doi.org/10.1016/j.jag.2007.11.002

[9] Schneider, P., Ghent, D., Corlett, G., Prata, F. and Remedios, J. (2012) AATSR Validation: LST Validation Protocol. University of Leicester, UK.

[10] Wan, Z. (2008) New Refinements and Validation of the MODIS Land-Surface Temperature/Emissivity Products. Remote Sensing of Environment, 112, 59-74. https://doi.org/10.1016/j.rse.2006.06.026

[11] Wang, W., Liang, S. and Meyers, T. (2008) Validating MODIS Land Surface Temperature Products Using Long-Term Nighttime Ground Measurements. Remote Sensing of Environment, 112, 623-635. https://doi.org/10.1016/j.rse.2007.05.024

[12] Lambin, E.F. and Ehrlich, D. (1996) The Surface Temperature-Vegetation Index Space for Land Cover and Land-Cover Change Analysis. International Journal of Remote Sensing, 17, 463-487. https://doi.org/10.1080/01431169608949021

[13] Olagunju, E.G. (2008) Remote Sensing for Agricultural Land Use Changes and Sustainability Monitoring in Sudan.

[14] Feldhake, C.M., Glenn, D.M. and Peterson, D.L. (1996) Pasture Soil Surface Temperature Response to Drought. Agronomy Journal, 88, 652-656. https://doi.org/10.2134/agronj1996.00021962008800040025x

[15] McVicar, T.R. and Jupp, D.L. (1998) The Current and Potential Operational Uses of Remote Sensing to Aid Decisions on Drought Exceptional Circumstances in Australia: A Review. Agricultural Systems, 57, 399-468. https://doi.org/10.1016/S0308-521X(98)00026-2

[16] Feizizadeh, B., Blaschke, T., Nazmfar, H., Akbari, E. and Kohbanani, H.R. (2013) Monitoring Land Surface Temperature Relationship to Land Use/Land Cover from Satellite Imagery in Maraqeh County, Iran. Journal of Environmental Planning and Management, 56, 1290-1315.

[17] Caselles, V. and Sobrino, J. (1989) Determination of Frosts in Orange Groves from NOAA-9 AVHRR Data. Remote Sensing of Environment, 29, 135-146. https://doi.org/10.1016/0034-4257(89)90022-9

[18] Becker, F. and Li, Z.-L. (1995) Surface Temperature and Emissivity at Various Scales: Definition, Measurement and Related Problems. Remote Sensing Reviews, 12, 225-253. https://doi.org/10.1080/02757259509532286

[19] Jiang, G.M., Li, Z.L. and Nerry, F. (2006) Land Surface Emissivity Retrieval from Combined Mid-Infrared and Thermal Infrared Data of MSG-SEVIRI. Remote Sensing of Environment, 105, 326-340. https://doi.org/10.1016/j.rse.2006.07.015

[20] Petitcolin, F. and Vermote, E. (2002) Land Surface Reflectance, Emissivity and Temperature from MODIS Middle and Thermal Infrared Data. Remote Sensing of Environment, 83, 112-134. https://doi.org/10.1016/S0034-4257(02)00094-9

[21] Cho, A.R. and Suh, M.S. (2013) Evaluation of Land Surface Temperature Operationally Retrieved from Korean Geostationary Satellite (COMS) Data. Remote Sensing, 5, 3951-3970. https://doi.org/10.3390/rs5083951 
[22] Schmetz, J., et al. (2002) An Introduction to Meteosat Second Generation (MSG). Bulletin of the American Meteorological Society, 83, 977-992.

[23] Wan, Z. and Dozier, J. (1996) A Generalized Split-Window Algorithm for Retrieving Land-Surface Temperature from Space. IEEE Transactions on Geoscience and Remote Sensing, 34, 892-905. https://doi.org/10.1109/36.508406

[24] Wan, Z., Zhang, Y., Zhang, Q. and Li, Z.-L. (2004) Quality Assessment and Validation of the MODIS Global Land Surface Temperature. International Journal of Remote Sensing, 25, 261-274. https://doi.org/10.1080/0143116031000116417

[25] Wan, Z. and Li, Z.-L. (2008) Radiance-Based Validation of the V5 MODIS Land-Surface Temperature Product. International Journal of Remote Sensing, 29, 5373-5395. https://doi.org/10.1080/01431160802036565

[26] Gao, C., Tang, B.-H., Wu, H., Jiang, X. and Li, Z.-L. (2013) A Generalized Split-Window Algorithm for Land Surface Temperature Estimation from MSG-2/SEVIRI Data. International Journal of Remote Sensing, 34, 4182-4199. https://doi.org/10.1080/01431161.2013.773408

[27] Biona, C.B., Druilhet, A., Benech, B. and Lyra, R. (2001) Diurnal Cycle of Temperature and Wind Fluctuations within an African Equatorial Rain Forest. Agricultural and Forest Meteorology, 109, 135-141. https://doi.org/10.1016/S0168-1923(01)00253-2

[28] Peres, L.F. and DaCamara, C.C. (2004) Land Surface Temperature and Emissivity Estimation Based on the Two-Temperature Method: Sensitivity Analysis Using Simulated MSG/SEVIRI Data. Remote Sensing of Environment, 91, 377-389. https://doi.org/10.1016/j.rse.2004.03.011

[29] Peres, L.F. and DaCamara, C.C. (2005) Emissivity Maps to Retrieve Land-Surface Temperature from MSG/SEVIRI. IEEE Transactions on Geoscience and Remote Sensing, 43, 1834-1844. https://doi.org/10.1109/TGRS.2005.851172

[30] Bailey, S.W. and Werdell, P.J. (2006) A Multi-Sensor Approach for the On-Orbit Validation of Ocean Color Satellite Data Products. Remote Sensing of Environment, 102, 12-23. https://doi.org/10.1016/j.rse.2006.01.015

[31] Freund, R.J. and Wilson, W.J. (2003) Statistical Method. 2nd Edition, Academic Press, San Diego, CA.

[32] Jin, M. and Dickinson, R.E. (2000) A Generalized Algorithm for Retrieving Cloudy Sky Skin Temperature from Satellite Thermal Infrared Radiances. Journal of Geophysical Research: Atmospheres, 105, 27037-27047. https://doi.org/10.1029/2000JD900318

[33] Ackerman, S.A., Holz, R.E., Frey, R., Eloranta, E.W., Maddux, B.C. and McGill, M. (2008) Cloud Detection with MODIS. Part II: Validation. Journal of Atmospheric and Oceanic Technology, 25, 1073-1086. https://doi.org/10.1175/2007JTECHA1053.1

[34] Kabsch, E., Olesen, F.S. and Prata, F. (2008) Initial Results of the Land Surface Temperature (LST) Validation with the Evora, Portugal Ground-Truth Station Measurements. International Journal of Remote Sensing, 29, 5329-5345. https://doi.org/10.1080/01431160802036326

[35] Klein, S.A. (1997) Synoptic Variability of Low-Cloud Properties and Meteorological Parameters in the Subtropical Trade Wind Boundary Layer. Journal of Climate, 10, 2018-2039. https://doi.org/10.1175/1520-0442(1997)010<2018:SVOLCP >2.0.CO;2

[36] Fan, J., Zhang, R., Li, G. and Tao, W.-K. (2007) Effects of Aerosols and Relative Humidity on Cumulus Clouds. Journal of Geophysical Research: Atmospheres, 112, 
D14204. https://doi.org/10.1029/2006JD008136

[37] Walcek, C. (1994) Cloud Cover and Its Relationship to Relative Humidity during a Springtime Midlatitude Cyclone. Monthly Weather Review, 122, 1021 p. https://doi.org/10.1175/1520-0493(1994)122<1021:CCAIRT>2.0.CO;2

[38] Samba, G. and Nganga, D. (2014) Minimum and Maximum Temperature Trends in Congo-Brazzaville: 1932-2010. Atmospheric and Climate Sciences, 4, 404-430.

[39] Gallo, K., Hale, R., Tarpley, D. and Yu, Y. (2010) Evaluation of the Relationship between Air and Land Surface Temperature under Clear- and Cloudy-Sky Conditions. Journal of Applied Meteorology and Climatology, 50, 767-775. https://doi.org/10.1175/2010JAMC2460.1

[40] Gao, C., Jiang, X., Wu, H., Tang, B., Li, Z. and Li, Z. (2012) Comparison of Land Surface Temperatures from MSG-2/SEVIRI and Terra/MODIS. Journal of Applied Remote Sensing, 6, Article ID: 063606. https://doi.org/10.1117/1.JRS.6.063606

[41] Zeng, L., et al. (2015) Estimation of Daily Air Temperature Based on MODIS Land Surface Temperature Products over the Corn Belt in the US. Remote Sensing, 7, 951 -970. https://doi.org/10.3390/rs70100951

[42] Lin, S., Moore, N.J., Messina, J.P., DeVisser, M.H. and Wu, J. (2012) Evaluation of Estimating Daily Maximum and Minimum Air Temperature with MODIS Data in East Africa. International Journal of Applied Earth Observation and Geoinformation, 18, 128-140. https://doi.org/10.1016/j.jag.2012.01.004

[43] Vancutsem, C., Ceccato, P., Dinku, T. and Connor, S.J. (2010) Remote Sensing of Environment Evaluation of MODIS Land Surface Temperature Data to Estimate Air Temperature in Different Ecosystems over Africa. Remote Sensing of Environment, 114, 449-465. https://doi.org/10.1016/j.rse.2009.10.002

[44] Li, H., et al. (2014) Evaluation of the VIIRS and MODIS LST Products in an Arid Area of Northwest China. Remote Sensing of Environment, 142, 111-121. https://doi.org/10.1016/j.rse.2013.11.014

[45] Hulley, G.C. and Hook, S.J. (2009) Intercomparison of Versions 4, 4.1 and 5 of the MODIS Land Surface Temperature and Emissivity Products and Validation with Laboratory Measurements of Sand Samples from the Namib Desert, Namibia. $R e-$ mote Sensing of Environment, 113, 1313-1318.

https://doi.org/10.1016/j.rse.2009.02.018 